This is an Authors' Accepted Manuscript of an article published in SPORT IN SOCIETY, online first February 2014, copyright Taylor \& Francis, available online at: http://www.tandfonline.com/doi/full/10.1080/17430437.2014.882906

\title{
Exploring Embodiment through Martial Arts and Combat Sports: A Review of Empirical Research
}

\author{
Alex Channon \\ University of Greenwich, London, UK \\ George Jennings \\ Universidad YMCA, Mexico City, Mexico \\ Corresponding Author: \\ Dr. Alex Channon, School of Education, University of Greenwich, Mansion Site, Bexley \\ Road, London SE9 2PQ \\ Tel: +44 (0)20 83318255 \\ Email: a.g.channon@gre.ac.uk
}




\title{
Exploring Embodiment through Martial Arts and Combat Sports: A Review of Empirical Research
}

\begin{abstract}
Since the late 1970s, social scientists have turned considerable attention to investigating martial arts and combat sports (MACS). In particular, this broad range of fighting disciplines has been shown to offer numerous avenues for scholarly enquiry into social change and personal transformation via processes of embodiment. Adopting a thematic structure, we assess the empirical literature in this area via four interconnecting categories pertaining to MACS and embodiment: (1) body cultures; (2) body pedagogies; (3) the embodiment of gender; and (4) bodily harm. Following this review, we identify several gaps in the existing literature, suggesting potential new topics and strategies for research connecting to the social world of physical culture more generally.
\end{abstract}

Keywords: Martial arts; self-defence; combat sports; review; embodiment; social science

Over the last 35 years, social scientific interest in martial arts and combat sports (MACS) has been expanding, with research articles published across an array of English language journals within the sociology of sport and related disciplines, as well as the publication of several academic books on specific fighting systems, ${ }^{1}$ and on MACS in general. ${ }^{2}$ Following Columbus and Rice's advocacy of a phenomenological approach to their study, ${ }^{3}$ MACS research since the late-1990s has begun to explore the subjective experiences and embodied insights of long-term practitioners, and more recent scholarship has owed much to Wacquant's oft-cited ethnography of boxing in a working-class Chicago gym - a prime example of such empirically rich work. ${ }^{4}$ Following this turn to the embodied/subjective aspects of MACS practice, research has sought to understand how practitioners' embodied experiences affect their own lives as well as the wider cultural settings and structures 
within which they are situated, and in this paper we attempt to provide an overview of this body of knowledge.

From the outset, it must be clearly stated that this review is concerned with work on embodiment, which we define as research centred on the living, moving and feeling social experiences of human beings. This approach is different to the sociology of the body, for instance, which primarily sets out to explore and test social theory as applied to the body. Thus, this review highlights studies with a paramount interest in the embodied experiences, sensations and life worlds of MACS practitioners, rather than those aiming to further or critique particular theoretical readings of bodies. These studies of embodiment are not restricted to a particular academic discipline or sub-discipline, as we found original research articles from a broad spectrum of social sciences relevant to this effort, including the sociology of sport, the sociology of the body, cultural and social anthropology, and sports pedagogy, alongside traditions spanning across disciplines, such as phenomenology and narrative approaches. Together, with the object (and in many cases, source and medium) of most studies being the thinking, moving and feeling bodies of practitioners (along with, in some others, such bodies' 'consumption' by spectators/fans), this constitutes our current 'field' of scholarly inquiry.

In order to summarise the trajectories upon which this research has taken shape, and with the aim of clarifying current gaps in knowledge and suggesting possible directions for future work, we identified four interconnected themes to help organise our review - 1) body cultures; 2) body pedagogies; 3 ) the embodiment of gender; and 4) bodily harm. Using these categories, we have arranged this paper as a series of thematic and sub-thematic commentaries, culminating in some recommendations for continued work in each area, with a further consideration of currently unexplored avenues for future research in our final conclusions.

Charting the existing literature was challenging, as there is no universally agreed definition of 'martial arts', a term which may be used to describe a variety of practices which bear many differences from one another, as much as similarities. ${ }^{5}$ Such practices could include codified, institutionally governed sporting disciplines such as boxing or Taekwondo; military or 'street' self-defence systems including Krav Maga; and traditionalist, mind-body disciplines, or 'Eastern movement forms', ${ }^{6}$ such as Kung $F u$ and Taijiquan. Complicating efforts at neatly defining or categorising these disparate arts is the recognition that, in individual practice, any given style may blur 
the conceptual boundaries upon which such typologies are based. Thus, we have adopted the aforementioned term 'martial arts and combat sports' (MACS), which we propose be used as an inclusive, triadic model encompassing competition-oriented combat sports, military/civilian self-defence systems, and traditionalist or noncompetitive martial arts, ${ }^{7}$ as well as activities straddling these boundaries. Overall however, what binds these differing types of 'martial arts' or 'combat sports' is a focus on the need to deal with the meanings and the problems associated with physical violence and human combat, which could take place within and between sporting, military or civilian circumstances, and could also be strategically proactive or reactive to perceived/direct aggression. Thus, our fundamental criteria for inclusion within the MACS model here involves the requirement of some form of orientation towards improving/measuring 'martial' or 'combative' abilities - regardless of how this is lived out in actual practice.

We met the complex task of conducting this review by working collaboratively and sharing bibliographical compilations with academic colleagues. As no single search engine provides complete access to all of the literature, we used a variety of academic search tools including Google Scholar, SportDiscus, Web of Science/Knowledge, and publishers' own databases. Academic books, book chapters, journal articles and a number of doctoral theses from a range of social science disciplines were included in the review, while papers from commercial journals geared towards MACS audiences (for instance, Journal of Asian Martial Arts) were excluded. ${ }^{8}$

While reviews of 'martial arts' research - typically conducted using this undifferentiated umbrella term - have been undertaken within the academic disciplines of psychology and education scholarship, ${ }^{9}$ this paper delivers the first systematic review of studies on embodiment, which now arguably constitute a field of their own. It is timely considering the recent publication of Sánchez García and Spencer's edited book, Fighting Scholars: Habitus and Ethnographies of Martial Arts and Combat Sports, a text consisting of various contemporary ethnographies within a broad range of MACS activities. At a time when research in the area is expanding rapidly, we hope this paper will offer other researchers some worthwhile perspectives on an enlarging and diverse field, which may also contribute to knowledge of embodiment, the body, and physical culture within the social sciences more generally. 


\section{Body Cultures: MACS as sites of embodied cultural transmission}

Studies which have interrogated the cultural meanings of MACS practice are numerous, and while all of the papers included in this review are concerned with 'culture' in some regard, this first section outlines those which deal with the transmission and transformation of specific/distinctive body cultures in MACS settings, covering: 1) research within specific, localised body cultures; 2) the globalisation and transmission of culturally-specific MACS; and 3) the resulting cross-cultural MACS practice.

Typically, the early English language studies of MACS (from the late 1970s to around the mid-1990s) focused on localised institutions, such as governing bodies, school structures, and their leadership. ${ }^{10}$ Much of the work here focused on the historical development, global diffusion, and cultural transformation of formal MACS organisations, ${ }^{11}$ with little comment or data on how these processes affected practitioners' embodied experiences. Some more recent analyses of such cultural institutions, however, have shown how transformations in these settings can impact at an embodied level, as the effects of culture upon bodies (and bodies upon culture) have been foregrounded. For instance, Downey's research into mixed martial arts (MMA) showed that fighting techniques are created and modified based upon institutional and cultural structures. ${ }^{12}$ Elsewhere, in their investigation of traditionalist martial arts' 'body lineage', Brown and Jennings have argued that practitioners' embodiment of technique can in turn shape these structures themselves, by helping to transmit (and possibly transform) embodied knowledge and forge a new generation of 'physical capital' resulting from a lifetime's investment in a 'living' art form. ${ }^{13}$

However, ethnographic work on specific, localised MACS subcultures has taken a far greater focus on issues relating to the enculturation of the body, as scholars began to explore the articulation of culture via the embodied practice of MACS. An early study examined Japanese-Okinawan martial arts such as Karate within the frame of broader institutional analyses, ${ }^{14}$ while more detailed and expansive ethnographies emerged in the 1990s, such as Alter's and Zarrilli's monographs on Indian wrestling and Kalarippayattu, respectively. ${ }^{15}$ Meanwhile, Paradis' recent account of boxing highlighted the effects of the sport's normative values on the embodied practices of boxers, with particular respect to broader societal norms of gender. ${ }^{16}$ 
While other research has explored various phenomena linked to the effects of culture on the body, such as Kohn's studies of identity formation and corporeal discipline in Aikido practice, ${ }^{17}$ perhaps the most prevalent themes in this area have concerned the transmission and transformation of the 'original' cultural meanings of today's 'globalised' MACS, which forms the second principle research area on body cultures. Beginning with Back and Kim's largely theoretical discussion of the changing nature of Eastern martial arts in the Western (and particularly North American) world during the late $20^{\text {th }}$ century, ${ }^{18}$ several authors have investigated how such arts, when disembedded from their 'home' settings, have been appropriated and altered by practitioners in different nations. For example, Krug considered the changes in Okinawan Karate following its integration into American body culture; ${ }^{19}$ Assunção explored the development of Capoeira from African tribal arts to today's global, cosmopolitan, Brazilian phenomenon; ${ }^{20}$ and Ryan explored the hybridisation of Taijiquan upon its introduction to Britain. ${ }^{21}$

A third area of research has begun to consider the blend of cultures seen in MACS practice, as cross-cultural comparative research has also proven popular. Dykhuizen's work on Aikido compared cultural meanings and interpretations of embodied energies and concepts between practitioners from its native Japan and the USA, ${ }^{22}$ and Samudra's ethnography of White Crane Silat in Indonesia, France and the USA identified anti-intellectual pedagogies that focused on forming embodied memory, despite cultural differences. ${ }^{23}$ The work of de Campos Rosario, Stephens and Delamont on Brazilian Capoeira teachers in Britain similarly speaks to such themes, ${ }^{24}$ while this field also includes examinations of immigrant communities looking to preserve a particular ethnic identity through MACS training, as with Carruthers' study of Vietnamese Vovinam in Australia. ${ }^{25}$

Further topics including ethnicity, 'race' and multiculturalism have been considered, in regards to the construction of national identities in China, ${ }^{26}$ resistance to racial stigmatisation in the USA, ${ }^{27}$ and the potential contribution of MACS for learning and dialogue between culturally diverse groups - wherein Judo has been suggested to be beneficial for immigrants integrating into Japanese society. ${ }^{28}$ However, issues pertaining to the significance of martial arts in multicultural societies nevertheless remain relatively under-researched in the current literature.

In summary, studies of MACS, the body and culture have thus focused upon three significant themes: 1) the embodiment of cultures and their embodied transmission 
via institutionalised arts and subcultural groups of practitioners; 2) their globalisation, assimilation and transformation in various national contexts; and 3) the resulting cultural mix within and between these international cultures. While the majority of this work has been conducted in East Asian, European or North American settings, researchers have also begun to consider these topics elsewhere, such as Latin America. ${ }^{29}$ Works which build upon existing knowledge about cross-cultural diffusion in the globalisation of MACS would do well to further explore how meanings, identities, and relations become embodied through training at a variety of culturally distinctive arts and systems. Additionally, the place of MACS in regulating distinctiveness and identity in multi-cultural societies is also a prescient theme which deserves more attention from scholars than it has so far received.

\section{Body Pedagogies: MACS as education of/through the body}

The educative potential of MACS via embodiment has been discussed and analysed by various researchers over the last few decades, and this work can be split into two sub-themes: 1) MACS as potential contributors to 'mainstream' education curricula; and 2) examinations of specific martial pedagogies.

The possible integration of Eastern martial arts into Western physical education (PE) systems has been a key concern for some scholars. ${ }^{30}$ In Britain, Sparkes called for 'martial movement sequences' to be included in PE in order to help students learn to move in different ways. ${ }^{31}$ This paper offered an early indication of possibilities, although like many earlier efforts, it did not contain data or a detailed theoretical approach. Meanwhile, in the US, Levine advocated the implementation of Aikido into 'liberal arts' education, suggesting that it could be used to teach various academic topics including culture, religion, or philosophy, ${ }^{32}$ while Clawson and Doner adopted a similar position in their discussion of Aikido and leadership training. ${ }^{33}$

In the early 2000s, Lantz adopted a phenomenological approach to explore the role of Eastern martial arts in aiding the development of family relationships. ${ }^{34}$ In a methodologically rare approach, both child practitioners and their parents were interviewed, and various benefits of training identified. Later, attention was turned more specifically to children's education through martial arts, when Theeboom, De Knop and Vertonghen investigated the experiences of children training in different 
disciplines. ${ }^{35}$ They asserted that differences in training approaches notwithstanding, MACS pedagogies tended to be useful in attaining a number of desirable social and psychological outcomes, including increased self-discipline and control of aggression.

Elsewhere, Brown and Johnson's paper suggested the more specific potential for self-defence martial arts to be included in PE curricula. ${ }^{36}$ In line with Sparkes' earlier argument, ${ }^{37}$ these authors posited that self-defence training develops certain bodily dispositions such as embodied sensitivity, which may offer novel sensations and experiences for pupils. This study may have paved the way for more theoreticallydriven articles, although to date no paper has adequately balanced theoretical, empirical and practical/political considerations regarding the pedagogical usefulness of martial arts in physical education, despite the subject having been discussed for almost thirty years. Thus, theoretically-grounded research highlighting the applications of MACS in formal physical education systems is certainly warranted in this case.

A second, more recent trend in research consists of ethnographic explorations of MACS in their own pedagogical environments, such as Bar-On Cohen's study of somatic communication in Karate. ${ }^{38}$ Such works have explored teaching strategies and philosophies, teacher-student interactions, and ideologies within specific organisations. Jennings' study, for instance, employed phenomenologically and narratively inspired investigation to explore how traditionalist Chinese martial arts training transformed practitioners, their institutions, and even the arts themselves through an embodied process of 'shared cultivation'. 39

Besides these and a handful of other studies, including Rao's account of disabilityinclusive curricula in Karate, ${ }^{40}$ and Wilson's study of the standardisation of Indonesian Pencak Silat pedagogies, ${ }^{41}$ Capoeira has been the focus of many recent pedagogical ethnographies. In the last decade, academic research on this dance-fightgame has grown rapidly, beginning with Downey's work on the social usefulness of teaching and learning strategies and the physical/cultural transmission of the art in localized groups in Brazil and the USA. ${ }^{42}$ Meanwhile, a sociological lens was added by Delamont and Stephens' collaborative study in Britain. ${ }^{43}$ Here, a specific Capoeira school and its instructor were examined, with a main focus on teaching methods, strategies to maintain authority and transmit culture. With Delamont as observer and Stephens as practitioner, these authors were able to paint a detailed picture of what it means to study an embodied art. Meanwhile, Joseph's study of a Canadian Capoeira 
organisation focused on culture and cultural transmission within a commercialised environment where culture is 'sold' to practitioners who want to 'go to Brazil' in physical/emotional/spiritual terms. ${ }^{44}$ Thus, practitioners' identities and cultural hybridity were also subjects of her pedagogical analysis.

Overall, the research on MACS pedagogy can be divided into two strands: 1) discussions of how these embodied activities may enhance educational curricula; and 2) ethnographic studies of specific pedagogies, often using the researchers' own embodied practice as a means to explore these topics. However, due to the lack of standardisation among disparate MACS disciplines, this second strand of work often does not explicitly draw out specific education policy implications. Research linking these two subdivisions of educational research would thus be helpful in future, but would need to avoid a generalised advocacy of 'martial arts' as vehicles for education, given the evident diversity of body pedagogies practiced among various MACS schools/disciplines. Regarding this diversity, further explorations of the use of culturally-specific martial arts in the informal educational practices of ethnic minority and immigrant communities could also be instructive. This would be a particularly fruitful course of action for sociologists of physical education working in diverse societies, linking with research on culture and identity formation/transformation, as advocated above.

\section{The Embodiment of Gender: Reproducing/subverting patriarchy through} MACS

Scholars interested in MACS have explored gender issues within various contexts, with significant attention having been paid to women's embodied involvement in various disciplines. ${ }^{45}$ While there has been a small amount of socio-historical research on women's MACS participation, ${ }^{46}$ a major research focus has been the feminist exploration of women's self-defence training. ${ }^{47}$ During the 1990 s and 2000 s, several ethnographic case studies conducted in North America highlighted how self-defence training enables women's resistance to patriarchal body culture by 'subverting' dominant gender ideologies; for instance, Guthrie argued that women's embodiment could be profoundly changed by martial arts, which involve an empowering cultivation of physical and mental agency. ${ }^{48}$ This notion was central in McCaughey's 
influential work, which asserted that women's participation could amount to a form of 'physical feminism', 49 an argument later echoed by De Welde, Hollander, and Noel. ${ }^{50}$ Together, these works suggest that women training in self-defence are able to reconstruct their gendered selves, rejecting notions of innate female weakness and violability, thereby coming to embody a 're-made', 'empowered' sense of femininity.

Contemporaneous with the research on women's practice of self-defence, several authors working in Western European, North American and Australasian contexts addressed shifting perceptions of womanhood as embodied through and within women's combat sports. Hargreaves' paper on women's boxing outlined some of the major controversies surrounding the sport from a broad, socio-historical perspective, ${ }^{51}$ while Halbert, Mennesson, and Lafferty and McKay focused on participants' experiences at more localised levels. ${ }^{52}$ While these authors all agreed that women's participation in combat sports could challenge patriarchal norms, they have also variously highlighted ways in which traditional sexual hierarchies were sustained in spite of (or through) women's participation - a theme also echoed in research on women's boxing in Trinidad ${ }^{53}$ and North Korea, ${ }^{54}$ and in discussion of the recent controversy surrounding female boxers' uniforms ahead of the London 2012 Olympics. ${ }^{55}$ These findings were also consistent with other work on women's selfdefence,${ }^{56}$ wrestling, ${ }^{57}$ and assorted martial arts, ${ }^{58}$ highlighting that despite its potential to 'empower' or 'liberate' women, such outcomes are never fully guaranteed.

Scholars interested in similar themes have also begun to examine mixed-sex training environments. Here, Channon proposed that mixed groups hold valuable potential for the subversion of patriarchal norms, owing to the possibility for men's and women's gendered subjectivities to be 'transformed' by the experience of training with partners of the opposite sex $;{ }^{59}$ a position reflected in McNaughton's recent autoethnographic account of her Muay Thai training. ${ }^{60}$ However, Guérandel and Mennesson highlighted how traditional hierarchies privileging men could be restated in mixed Judo training, ${ }^{61}$ while Channon and Jennings agreed, noting that men's sense of chivalry often rendered hitting or otherwise touching women in training problematic, hindering the transformative potential of various MACS disciplines. ${ }^{62}$ Thus, mixed practice presents similar opportunities and challenges as those identified in earlier research on women's training. 
While there have been numerous studies on men's MACS participation, 'gender' itself is not always directly analysed, unlike with women's participation, where the socially problematic relationship between femininity and fighting normally sees the topic prioritised. Among the few works which explicitly look at men and masculinities, critical interrogations of the construction and contestation of masculinity in martial settings has been an important theme, ${ }^{63}$ particularly in recent studies of MMA. ${ }^{64}$ A key line of enquiry here has been the association between masculinity and violence, an important theme in earlier sociological enquiries into other 'male' sports cultures. Hirose and Pih compared American and Asian masculinities to explain how American MMA spectators often 'feminise' grappling matches due to their less obviously violent nature than striking-based fights. ${ }^{65}$ However, Mayeda and Ching assert that despite its media image as an extremely violent, 'macho' sport, (American) MMA practitioners themselves strongly reject the link between masculinity, MMA and violence. ${ }^{66}$

This disparity between the mass-mediation of MMA and fighters/aficionados' experiences is a telling theme, as several ethnographers have discussed MMA fighters' experiences by downplaying the importance of masculinity altogether. Abramson and Modzelewski argued that masculinity holds little relevance to MMA practitioners, and noted that male fighters welcomed women into their gyms, refusing to view the sport as exclusively male/'masculine'. ${ }^{67}$ Green agrees, noting that concerns about their gender identity make up only a minor part of what it means for men to be involved in MMA. ${ }^{68}$ However, Spencer argues that masculinity remains significant to practitioners, positing that they often tend to accept and reproduce some elements of a traditional, dominant/dominating, 'alpha-male' identity. ${ }^{69}$ Nevertheless, all these scholars suggest that male MMA practitioners routinely engage in otherwise 'feminised' behaviours, such as emotional openness, tactility, and intimacy with other men, without fear of the homosexualisation possibly accompanying such things in broader male cultural spaces. As such, it is possible that (some) MMA training cultures are conducive to less narrowly-defined and more inclusive visions of male identity than their 'macho' mediated image would imply.

Men's participation has been examined from a gender-sensitive perspective among other disciplines as well, perhaps most notably boxing, ${ }^{70}$ wherein race and social class intersectionality has also been a prominent theme. ${ }^{71}$ Similar issues emerge as with the recent work on MMA, including the place of violence in the maintenance or 
contestation of 'hegemonic' forms of male identity; men's (changing) relationships with other men; and their attitudes towards women.

In sum, gender has been an important issue for MACS research, and the literature frequently points to the potential for such training to challenge 'hegemonic', patriarchal orthodoxies via participants' embodied transformations. There is currently a great deal of ethnographic work on predominantly single-sex groups, but there remains a need for more studies attentive to mixed-sex training among various disciplines. Other topics for research which would be beneficial here include investigations explicitly focusing on sexuality in MACS cultures; explorations of women's experiences of MMA and their portrayal in the sport's emergent media coverage; more cross-cultural studies of masculinities and femininities in different cultural and political contexts; and more historical research on the development of women's engagement with MACS, in both Western and Eastern settings.

\section{Bodily Harm: Violence, pain and injury in MACS}

Research on MACS has long taken a considerable interest in the issue of 'violence', most notably in the fields of philosophy ${ }^{72}$ and psychology ${ }^{73}$ Here, claims that martial arts promote non-violence and the control of aggression have been debated and measured within numerous contexts. Within sociological literature though, the 'violence' involved with MACS has been explored principally through: 1) the contested ideological meanings of the bodily capacity to inflict or endure physical harm; and 2) the embodied experiences of pain and injury among practitioners.

Physical violence has, as alluded to above, been a key topic for gender researchers. Women's resistance to (and rehabilitation from) men's violence has been a central theme in the feminist investigations of women's self-defence arts, while the link between violence and masculine identity is another important aspect of this field. In this second regard, researchers have examined military-derived systems of selfdefence - Bar-On Cohen's ethnographic work on Israeli military Krav Maga and Jujutsu being of particular note. ${ }^{74}$ Here, the embodiment of masculinity in nationalistic settings was centralized by a focus on the performance and endurance of violence through/against practitioners' bodies, as physical violence becomes an important medium for engendering and expressing particular identities. This research 
had much to say about how ideologies and discourses were being transmitted through a pedagogy, but relatively little on how practitioners actually interpreted this.

Elsewhere, much attention is being given to the cultural diffusion and consumption of MMA, which quickly garnered a reputation for being an excessively 'violent' combat sport following its emergence in the 1990s. Downey has explored the creation and diffusion of MMA through Marcel Mauss's 'body techniques', ${ }^{75}$ whereby the levels of violence from practitioner and spectator perspectives differed in terms of embodied knowledge of their potential devastation. ${ }^{76}$ This has been accompanied by the debate between Sánchez García and Malcolm ${ }^{77}$ and Van Bottenburg and Heilbron, ${ }^{78}$ on the 'civilising' and 'decivilising' aspects of changes involved in this combat sport, wherein institutional changes in the Ultimate Fighting Championship have primarily revolved around regulating what practitioners' bodies are allowed to do in competitive fights. The debate here has been articulated through Eliasian concepts pertaining to violence, the body, and civilisation, echoing themes seen elsewhere in historical combat sports sociology. ${ }^{79}$

Scholars have also been directly attentive to MMA audiences. Topics have included Christian MMA fans negotiating the meanings of fighting, ${ }^{80}$ broader motivators for watching MMA in the $\mathrm{US}^{81}$ and the philosophical differences on violent masculinities between American and Asian audiences. ${ }^{82}$ These have made an important contribution in order to consider the connections between the embodied practice of an art with its mediation and the consumers/viewers that sustain its social field, which invites further investigation of the disparity between cultural representations of 'violence' in combat sports, with practitioners' perspectives on the meanings and significance of their combative exploits.

Regarding issues of pain, injury and practitioner experiences, a second area of research has outlined how (and why) MACS practitioners routinely subject themselves to physical pain, and concurrently risk injury, as an element of training. This is often related to physical, mental or spiritual development in their art; for instance, Bar-On Cohen's study of Kibadachi exercises in Karate highlighted the use of sustained, excruciating pain as a technique for engendering a specific 'warrior' mentality. ${ }^{83}$ This is not dissimilar to Downey's or Spencer's accounts of the role of pain in MMA training; ${ }^{84}$ central to a fighter's embodiment of combative prowess, the ability to both endure pain and deliver it to others is something for which practitioners must constantly prepare, as they transform their bodies through what Spencer 
describes as a process of 'body callusing, ${ }^{85}$ Similarly, Wacquant earlier suggested that in boxing, such asceticism in training is a necessary step in accumulating the 'bodily capital' required of elite/professional prizefighters. ${ }^{86}$

Further, Green described how MMA practitioners endure pain and risk injury not only in order to prepare their bodies for combat, but also as a signal of authenticity: that of the activity, their own bodies, and their place within the social setting of the art. ${ }^{87}$ Pain in this context becomes a way to substantiate both the 'realness' of the activity, and legitimise practitioners' identities as martial artists. Spencer also discusses the role of bodily harm in shaping an identity in MMA, as pain, and concurrent injuries sustained during practice, become integral to male martial artists' identities as fighters and, tellingly, as men. ${ }^{88}$

Issues pertaining to bodily harm have most recently been investigated via interrogating the experiences of men training in combat sports, primarily among male professional boxers and mixed martial artists. Studies focusing on women's participation would do well to explore women's negotiation of bodily harm in similar settings, since this aspect of men's training is considered to be bound up with performances of gender, possibly making for a potentially interesting contribution to debates over 'female masculinities', for instance. Meanwhile, given that the deliberate cause of harm to the body (of oneself and others) should feature as an element of male fighters' masculinities invites a more directly feminist critique of MMA, which is yet missing from among the growing collection of ethnographies on this emerging sport. Comparative analyses between prize-fighting disciplines and 'traditionalist' or selfdefence systems would also likely be instructive, particularly if informed by a sensitivity towards the cultural significance of such different fighting genres. ${ }^{89}$ Finally, direct comparisons between the expectations of fans/consumers, and the lived experiences of practitioners, are needed in order to better understand the social production of bodily harm associated with professional, mass-mediated, and consumer-driven prize-fighting disciplines.

\section{Conclusions}

In collating this review we have attempted to subsume a diverse collection of works deriving from various social science disciplines within four themes related to the 
increasingly important theme of embodiment: 1) body cultures; 2) body pedagogies; 3) the embodiment of gender; and 4) bodily harm. Work on MACS and embodiment has tended to coalesce around these themes, and it is our hope that this review can help to provide a platform for future efforts in the field.

Our framework is not without limitations; the boundaries between these topical themes are in fact blurred in the reality of the social practice of MACS, while several other categories might have been instructive and may have seen the inclusion of other notable studies. Nevertheless, we focused on works which we felt were the most significant and instructive to issues pertaining to practitioners' embodiment, a key topic within the sociology of sport and cognate disciplines. For example, we omitted a large body of writing on MACS films, typically composed by media scholars (with the majority of studies analysing the representation rather than the action and experience of the body), and did not account for a large number of psychological studies of MACS. Finally, we have focused on works available in English, which limits the scope of our analysis, thereby inviting future contributions of this type from multi-lingual researchers around the world. ${ }^{90}$

Throughout this review, we have called for further social scientific enquiry into currently under-researched areas relating to MACS and embodiment. Within the research into body cultures, investigations into a variety of MACS would do well to further consider distinctiveness and identity in multi-cultural societies, such as shedding light on the embodied experiences of immigrant communities engaged in culturally-specific martial practices. In terms of pedagogic research, there is a need for greater balance between theoretical, empirical and practical/political considerations. This work would further benefit from considering the concept of MACS as inclusive of a range of philosophically/practically differentiated, yet sometimes overlapping activities, and also from recognising that many MACS are today typically taught within mixed-sex environments, presenting unique opportunities for gender analyses. Finally, both gender and violence are themes which could be enhanced via research comparing experiences of practitioners with the viewpoints of fans and the mass media, and with comparative studies between combat sports and more traditionalist martial arts, extending the study of singular arts/systems in various directions.

In addition, we consider several substantive issues to be particularly conspicuous in their absence from the literature. Firstly, research has rarely focused on martial 
artistry and sexualities, and given recent attention among wider sociology of sport scholarship to the interplay of sport, the body and sexuality, this is a pertinent area for further investigation. Secondly, participants' positioning within philosophical frameworks stressing self-defence, cultural tradition, and/or competitive fighting need to be comparatively examined in order to present an up-to-date view of the social significance and meanings of various MACS, which will also inform investigations of their pedagogical purposes and usefulness for physical education curricula. Thirdly, as MACS are (re)invented and 'lost' throughout the world, this brings with it plenty of scope for contemporary research on the impact of institutions and social forces (such as globalisation) on the body cultures represented by distinctive, transforming and hybridising martial disciplines.

Due to the complexity of such issues, various methodological and theoretical strategies may be required. In addition to well-established methods such as ethnography, interviewing, or documentary analysis, methods such as examining online forums, netographies and (auto)biographies of teacher-practitioners may be useful to explore online articulations of martial cultures within mass media and broader fan bases, ${ }^{91}$ and how these relate to the experiences of practitioners themselves.

Finally, we would assert that more explicit engagements with political and policy issues may be useful as scholars attempt to draw links between the specific, highly abstract worlds of MACS philosophy and practice, with the more tangible realm of policy interventions and recommendations. Together, this would enable scholars to better contribute in terms of theory, topic and, when relevant, advocacy, as part of a broader, engaged social science of MACS and embodiment. We hope this review may prove to be a useful stepping-stone in others' efforts towards such ends.

\section{Notes}

1 Downey, Learning Capoeira; Spencer, Ultimate Fighting; Zarrilli, When the Body.

2 Farrer and Whalen-Bridge, Martial Arts; Green and Svinth, Martial Arts; Sánchez García and Spencer, Fighting Scholars.

3 Columbus and Rice, 'Psychological Research'; 'Phenomenological Meanings'.

4 Wacquant, Body \& Soul. Having already been exhaustively reviewed and critiqued - see Qualitative Sociology, vol.28 no.2 - we have decided to turn our attention to less well-known empirical works, mentioning Wacquant's study only briefly.

5 Exact terms used are often further broken down as 'disciplines', 'systems', 'arts', etc., depending on the prevailing culture of a given activity. We have accordingly respected such conventions in our review. 
Brown and Leledaki, 'Eastern Movement Forms'.

Importantly, we do not restrict our conceptualisation of 'traditionalist' martial arts purely to the 'Eastern' styles with which the phrase is most often associated in everyday parlance, as such practices actually derive from many cultures around the world - see Green and Svinth, Martial Arts.

8 While some social scientific research has been published in such journals (e.g. Schneider, 'Learning India's Martial Art'; Looser, 'The Risk Society'), the generally commercial orientation of these sources, and their typical target audience of MACS instructors and practitioners, might necessitate a separate review.

9 Columbus and Rice, 'Psychological Research'; Cox, 'Traditional Asian Martial Arts'; Fuller, 'Martial Arts'; Kavoura, Ryba and Kokkonen, 'Psychological Research'; Vertonghen and Theeboom, 'The Social-Psychological Outcomes'.

${ }^{10}$ Goodger and Goodger, 'Judo in the Light'; 'Organisational and Cultural Change'.

11 Saeki, 'The Conflict Between'; Theeboom and DeKnop, 'An Analysis'.

12 Downey, 'Producing Pain'.

13 Brown and Jennings, 'Body Lineage'.

14 James and Jones, 'The Social World'.

15 Alter, The Wrestler's Body; Zarrilli, When the Body.

16 Paradis, 'Boxers, Briefs or Bras?'.

17 Kohn, 'The Aikido Body'; 'Creatively Sculpting'.

18 Back and Kim, 'The Future Course'.

19 Krug, 'At the Feet'.

20 Assunção, Capoeira: The History.

21 Ryan, 'Globalisation and the Internal'.

22 Dykhuizen, 'Training in Culture'.

23 Samudra, 'Memory in Our Body'.

24 de Campos Rosario, Delamont and Stephens, 'I'm your Teacher!'; Stephens and Delamont, 'Roda Boa'.

25 Carruthers, 'Kung Fu Fighting'.

${ }^{26}$ Frank, 'Taijiquan and the Search'.

27 Wyrod, 'Warriors of the South'.

28 Ito et al., 'The Role of Leisure'.

29 Ryan, 'I did not Return'.

30 Theeboom and De Knopp, 'Asian Martial Arts'.

31 Sparkes, 'Martial Movement Sequences'.

32 Levine, 'The Liberal Arts'; 'Martial Arts'.

33 Clawson and Doner, 'Teaching Leadership'.

34 Lantz, 'Family Development'.

35 Theeboom, De Knop and Vertonghen, 'Experiences of Children'.

36 Brown and Johnson, 'The Social Practice'.

37 Sparkes, 'Martial Movement Sequences'.

38 Bar-On Cohen, 'Kime and the Moving Body'.

39 Jennings, 'Fighters, Thinkers'.

40 Rao, 'Oos Sensai!'.

41 Wilson, 'Jurus, Jazz Riffs'.

42 Downey, Learning Capoeira; 'Listening to Capoeira'; 'Scaffold Imitation'.

43 Delamont, 'The Smell of Sweat'; Delamont and Stephens, 'Balancing the Berimbau'; 'Up on the Roof'; Stephens and Delamont, 'Roda Boa'. See also de Campos Rosario, Delamont and Stephens, 'I'm your Teacher!'.

44 Joseph, 'Going to Brazil'; 'The Logical Paradox'.

45 In a recent essay, Follo claimed that female martial artists have historically been 'hidden' from the research literature, yet we contend that within the broader conceptualisation of MACS which we employ, it is evident that women's participation has been the subject of a number of widely-cited studies over the past two decades (listed below) - see Follo, 'A Literature Review'.

46 E.g. Jones, 'In Pursuit of Empowerment'; Looser, 'Radical Bodies'.

47 Searles and Berger, 'The Feminist Self-Defence Movement'; see Brecklin, 'Evaluation Outcomes', for a review of quantitative psychological studies of women's self-defence. 
Guthrie, 'Liberating the Amazon'; 'Defending the Self'; Castelnuovo and Guthrie, Feminism and the Female Body.

49 McCaughey, Real Knockouts; 'The Fighting Spirit'.

50 De Welde, 'Getting Physical'; Hollander, 'I Can Take Care'; Noel, 'Un-Doing Gendered Power'.

51 Hargreaves, 'Women's Boxing'.

52 Halbert, 'Tough Enough'; Mennesson, 'Hard Women'; Lafferty and McKay, 'Suffragettes in Satin Shorts?'.

53 McCree, 'The Death'.

54 Lee, 'Red Feminism'.

55 Van Ingen and Kovacs, 'Subverting the Skirt'.

56 Hollander, 'The Roots of Resistance'.

57 Sisjord, 'Wrestling with Gender'; Sisjord and Kristiansen, 'Elite Women Wrestlers' Muscles'.

58 Velija, Mierzwinski and Fortune, 'It Made me Feel Powerful'.

59 Channon, 'Way of the Discourse'; 'Do you Hit Girls?'.

${ }^{60}$ McNaughton, 'Insurrectionary Womanliness'.

${ }^{61}$ Guérandel and Mennesson, 'Gender Construction'.

${ }^{62}$ Channon and Jennings, 'The Rules of Engagement'.

63 Chapman, 'Ossu! Sporting Masculinities'.

64 Holthuysen, 'Embattled Identities'.

65 Hirose and Pih, 'Men who Strike'.

66 Mayeda and Ching, Fighting for Acceptance.

${ }_{67}$ Abramson and Modzelewski, 'Caged Morality'.

68 Green, 'It Hurts'.

69 Spencer, Ultimate Fighting; 'Narratives of Despair'.

70 De Garis, 'Be a Buddy'; Matthews, 'The Thrill of the Fight'; Woodward, Boxing, Masculinity and Identity; 'Rumbles in the Jungle'.

71 Rhodes, 'Fighting for Respectability'; Wacquant, Body \& Soul.

72 Back and Kim, 'Towards a Western Philosophy'.

73 See note 9 , above.

74 Bar-On Cohen, 'Survival, an Israeli Ju Jutsu School'; 'Globalisation of the War'; 'Once We Put Our Helmets On'.

75 Downey, 'Producing Pain'.

76 See also Spencer, Ultimate Fighting.

77 Sánchez García and Malcolm, 'Decivilizing, Civilizing, or Informalizing?'.

78 Van Bottenburg and Heilbron, 'De-Sportization of Fighting Contests'; 'Informalization or DeSportization'.

79 Sheard, 'Aspects of Boxing'.

80 Borer and Schafer, 'Culture War Confessionals'.

81 Kim et al., 'An Analysis'.

82 Hirose and Pih, 'Men Who Strike'; Kim, Andrew and Greenwell, 'An Analysis'.

83 Bar-On Cohen, 'Kibadachi in Karate'.

${ }_{85}^{84}$ Downey, 'Producing Pain'; Spencer, 'Narratives of Despair'.

85 Spencer, 'Habit(us), Body Techniques'.

86 Wacquant, Body \& Soul; 'Pugs at Work'.

87 Green, 'It Hurts'.

${ }^{88}$ Spencer, 'Narratives of Despair'.

89 E.g. Channon, 'Western Men'.

90 Recent efforts in French, including Mennesson, 'Être une Femme', and in Spanish, such as Sánchez García, 'Análisis Etnometodológico' and Martínez Guirao, 'Una Aproximación Antropológica', may provide initial points of departure for similar reviews outside of the Anglophone literature.

91 E.g. Borer and Schafer, 'Culture War Confessionals'.

\section{References}


Abramson, Corey M., and Darren Modzelewski. 'Caged Morality: Moral Worlds, Subculture, and Stratification among Middle-Class Cage-Fighters'. Qualitative Sociology 34, no. 1 (2011): 143-75.

Alter, Joseph S. The Wrestler's Body: Identity and Ideology in North India. Berkeley, CA: University of California Press, 1992.

Assunção, Matthias R. Capoeira: The History of an Afro-Brazilian Martial Art. London: Routledge, 2005.

Back, Allan, and Daeshik Kim. 'The Future Course of the Eastern Martial Arts'. Quest 36, no. 1 (1984): 7-14.

Back, Allan, and Daeshik Kim. 'Towards a Western Philosophy of the Eastern Martial Arts'. Journal of the Philosophy of Sport 6, no. 1 (1979): 19-28.

Bar-On Cohen, Einat. 'Globalisation of the War on Violence: Israeli Close-Combat, Krav Maga and Sudden Alterations in Intensity'. Social Anthropology 18, no. 3 (2010): 267-88.

Bar-On Cohen, Einat. 'Kibadachi in Karate: Pain and Crossing Boundaries within the 'Lived Body' and Within Sociality'. Journal Of The Royal Anthropological Institute 15, no. 3 (2009): 610-29.

Bar-On Cohen, Einat. 'Kime and the Moving Body: Somatic Codes in Japanese Martial Arts'. Body \& Society 12, no. 1 (2006): 73-93.

Bar-On Cohen, Einat. 'Once We Put Our Helmets On, There are No More Friends: The 'Fights' Session in the Israeli Army Course for Close-Combat Instructors'. Armed Forces and Society 37, no. 3 (2011): 512-33.

Bar-On Cohen, Einat. 'Survival, an Israeli Ju Jutsu School of Martial Arts: Violence, Body, Practice and the National'. Ethnography 10, no. 2 (2009): 153-83.

Borer, Michael I., and Tyler S. Schafer. 'Culture War Confessionals: Conflicting Accounts of Christianity, Violence and Mixed Martial Arts'. Journal of Media and Religion 10, no. 4 (2011): 165-84.

Brecklin, Leanne R. 'Evaluation Outcomes of Self-Defence Training for Women: A Review' Aggression and Violent Behaviour 13, no. 1 (2009): 60-76.

Brown, David, and George Jennings. 'Body Lineage: Conceptualising the Transmission of Traditional Asian Martial Arts in the West'. STAPS 32 (2011): 6172.

Brown, David, and Alan Johnson. 'The Social Practice of Self-Defence Martial Arts: Applications for Physical Education'. Quest 52, no. 3 (2000): 246-59.

Brown, David, and Aspasia Leledaki. 'Eastern Movement Forms as Body-Self Transforming Cultural Practices in the West: Towards a Sociological Perspective'. Cultural Sociology 4, no. 1 (2010): 123-54.

Carruthers, Ashley. 'Kung Fu Fighting: The Cultural Pedagogy of the Body in the Vovinam Vietnamese Martial Arts School'. Australian Journal of Anthropology 9, no. 1 (1998): 45-57.

Castelnuovo, Shirley and Sharon R. Guthrie. Feminism and the Female Body: Liberating the Amazon Within. London: Lynne Rienner Publishers, 1998.

Channon, Alex. "“Do you Hit Girls?" Some Striking Moments in the Career of a Male Martial Artist'. In Fighting Scholars: Habitus and Ethnographies of Martial Arts 
and Combat Sports, edited by Raúl Sánchez García and Dale C. Spencer, 95-110. London: Anthem Press, 2013.

Channon, Alex. 'Way of the Discourse: Mixed-Sex Martial Arts and the Subversion of Gender'. PhD diss., Loughborough University, UK, 2012.

Channon, Alex. 'Western Men and Eastern Arts: The Significance of Eastern Martial Arts Disciplines in British Men's Narratives of Masculinity'. Asia Pacific Journal of Sport and Social Science 1, no. 2-3 (2012): 111-27.

Channon, Alex, and George Jennings. 'The Rules of Engagement: Negotiating Painful and "Intimate" Touch in Mixed-Sex Martial Arts'. Sociology of Sport Journal 30, no. 4 (2013): 487-503.

Chapman, Kris. 'Ossu! Sporting Masculinities in a Japanese Karate Dojo'. Japan Forum 16, no. 2 (2004): 315-35.

Clawson, James G., and Jonathan Doner. 'Teaching Leadership through Aikido'. Journal of Management Education 20, no. 2 (1996): 182-205.

Columbus, Peter J., and Don L. Rice. 'Phenomenological Meanings of Martial Arts Participation'. Journal of Sport Behaviour 21, no. 1 (1998): 16-28.

Columbus, Peter J., and Don L. Rice. 'Psychological Research on the Martial Arts: An Addendum to Fuller's Review'. British Journal of Medical Psychology 64, no. 2 (1991): 127-35.

Cox, John C. 'Traditional Asian Martial Arts Training: A Review'. Quest 45, no. 3 (1993): 366-88.

De Campos Rosario, Claudio, Neil Stephens, and Sara Delamont. "“I'm your Teacher! I'm Brazilian!" Authenticity and Authority in European Capoeira'. Sport, Education \& Society 15, no. 1 (2010): 103-20.

De Garis, Laurence. “"Be a Buddy to Your Buddy": Male Identity, Aggression, and Intimacy in a Boxing Gym'. In Masculinities, Gender Relations, and Sport, edited by Jim McKay, Michael A. Messner and Don Sabo, 87-107. London: Sage, 2000.

De Welde, Kristine. 'Getting Physical: Subverting Gender through Self-Defence'. Journal of Contemporary Ethnography 32, no. 3 (2003): 247-78.

Delamont, Sara. 'The Smell of Sweat and Rum: Teacher Authority in Capoeira Classes'. Ethnography and Education 1, no. 2 (2006): 161-75.

Delamont, Sara, and Neil Stephens. 'Balancing the Berimbau: Embodied Ethnographic Understanding'. Qualitative Inquiry 12, no. 2 (2006): 316-39.

Delamont, Sara, and Neil Stephens. 'Up on the Roof: The Embodied Habitus of Diasporic Capoeira'. Cultural Sociology 2, no. 1 (2008): 57-74.

Downey, Greg. Learning Capoeira: Lessons in Cunning from an Afro-Brazilian Martial Art. Oxford: Oxford University Press, 2005.

Downey, Greg. 'Listening to Capoeira: Phenomenology, Embodiment and the Materiality of Music. Ethnomusicology 46, no. 3 (2006): 487-509.

Downey, Greg. 'Producing Pain: Techniques and Technologies in No-Holds-Barred Fighting'. Social Studies of Science 37, no. 2 (2007): 201-26.

Downey, Greg. 'Scaffold Imitation in Capoeira: Physical Education and Enculturation in an Afro-Brazilian Art'. American Anthropologist 110, no. 2 (2008): 204-13. 
Dykhuizen, Jeffrey. 'Training in Culture: The Case of Aikido Education and Meaning Making Outcomes in Japan and the United States'. International Journal of Intercultural Relations 24, no. 6 (2000): 741-61.

Farrer, D.S., and John Whalen-Bridge, eds. Martial Arts as Embodied Knowledge: Asian Traditions in a Transnational World. New York: SUNY Press, 2011.

Follo, Giovanna. 'A Literature Review of Women and the Martial Arts: Where are we Right Now?' Sociology Compass 6, no. 9 (2012): 707-17.

Frank, Adam D. 'Taijiquan and the Search for Little Old Chinese Man: Ritualizing Race Through Martial Arts'. PhD diss., The University of Texas at Austin, US, 2003.

Fuller, Julian R. 'Martial Arts and Psychological Health'. British Journal of Medical Psychology 61, no. 4 (1988): 317-28.

Goodger, Brian C., and John M. Goodger. 'Judo in the Light of Theory and Sociological Research'. International Review of Sport Sociology 12, no. 2 (1977): 5-34.

Goodger, Brian C., and John M. Goodger. 'Organisational and Cultural Change in Post-War British Judo'. International Review for the Sociology of Sport 15, no. 1 (1980): 21-48.

Green, Kyle. 'It Hurts so it is Real: Sensing the Seduction of Mixed Martial Arts'. Social \& Cultural Geography 12, no. 4 (2011): 377-96.

Green, Thomas A., and Joseph R. Svinth, eds. Martial Arts in the Modern World. Westport, CT: Greenwood Publishing, 2003.

Guérandel, Carine, and Christine Mennesson. 'Gender Construction in Judo Interactions'. International Review for the Sociology of Sport 42, no. 2 (2007): 167-86.

Guthrie, Sharon R. 'Defending the Self: Martial Arts and Women's Self-Esteem'. Women in Sport \& Physical Activity Journal 6, no. 1 (1997): 1-28.

Guthrie, Sharon R. 'Liberating the Amazon: Feminism and the Martial Arts'. Women \& Therapy 16, no.2-3 (1995): 107-19.

Halbert, Christy. 'Tough Enough and Woman Enough: Stereotypes, Discrimination, and Impression Management Among Women Professional Boxers'. Journal of Sport and Social Issues 21, no. 1 (1997): 7-36.

Hargreaves, Jennifer. 'Women's Boxing and Related Activities: Introducing Images and Meanings. Body \& Society 3, no. 4 (1997): 33-49.

Hirose, Akihiko, and Kay Kei-Ho Pih. 'Men Who Strike and Men Who Submit: Hegemonic and Marginalized Masculinities in Mixed Martial Arts'. Men and Masculinities 13, no. 2 (2010): 190-209.

Hollander, Jocelyn A. "II Can Take Care of Myself”: The Impact of Self-Defence Training on Women's Lives'. Violence Against Women 10, no. 3 (2004): 205-35.

Hollander, Jocelyn A. 'The Roots of Resistance to Women's Self-Defence'. Violence Against Women 15, no. 5 (2009): 574-94.

Holthuysen, Jamie. 'Embattled Identities: Constructions of Contemporary American Masculinity Amongst Mixed Martial Arts Cagefighters'. PhD diss., Arizona State University, US, 2011. 
Ito, Eiji, Haruo Nogawa, Kaoru Kitamura, and Gordon J. Walker. 'The Role of Leisure in the Assimilation of Brazilian Immigrants into Japanese Society: Acculturation and Structural Assimilation through Judo Participation'. International Journal of Sport and Health Science 9 (2011): 8-14.

James, Alan, and Richard Jones. 'The Social World of Karate-Do'. Leisure Studies 1, no. 3 (1982): 337-54.

Jennings, George B. 'Fighters, Thinkers and Shared Cultivation: Experiencing Transformation through the Long-Term Practice of Traditionalist Chinese Martial Arts'. PhD diss., University of Exeter, UK, 2010.

Jones, Denise E.M. 'In Pursuit of Empowerment: Sensei Nellie Kleinsmot, Race and Gender Challenges in South Africa'. The International Journal of the History of Sport 18, no. 1 (2001): 219-36.

Joseph, Janelle. “'Going to Brazil": Transnational and Corporeal Movements of a Canadian-Brazilian Martial Arts Community’. Global Networks 8, no. 2 (2008): 194-213.

Joseph, Janelle. 'The Logical Paradox of the Cultural Commodity: Selling an "Authentic" Afro-Brazilian Martial Art in Canada'. Sociology of Sport Journal 25, no. 4 (2008): 498-515.

Kavoura, Anna, Tatiana V. Ryba, and Marja Kokkonen. 'Psychological Research on Martial Arts: A Critical View from a Cultural Praxis Framework'. Scandinavian Sports Studies Forum 3 (2012): 1-23.

Kim, Seungmo, Damon P.S. Andrew, and T. Christopher Greenwell. 'An Analysis of Spectator Motives and Media Consumption Behaviour in an Individual Combat Sport: Cross National Differences between American and South Korean Mixed Martial Arts Fans. International Journal of Sports Marketing and Sponsorship 10, no. 2 (2009): 157-70.

Kim, Seungmo, T. Christopher Greenwell, Damon P.S. Andrew, Janghyuk Lee, and Daniel F. Mahony. 'An Analysis of Spectator Motives in an Individual Combat Sport: A Study of Mixed Martial Arts Fans'. Sport Marketing Quarterly 17, no. 2 (2008): 109-19.

Kohn, Tamara. 'Creatively Sculpting the Self through the Discipline of Martial Arts Training'. In Exploring Regimes of Discipline, edited by Noel Dyck, 99-112. New York: Berghahn Books, 2008.

Kohn, Tamara. 'The Aikido Body: Expressions of Group Identities and SelfDiscovery in Martial Arts Training'. In Sport, Dance and Embodied Identities, edited by Noel Dyck and Eduardo P. Archetti, 139-55. Oxford: Berg, 2003.

Krug, Gary J. 'At the Feet of the Master: Three Stages in the Appropriation of Okinawan Karate into Anglo-American Culture'. Cultural Studies $\leftrightarrow$ Critical Methodologies 1, no. 4 (2001): 395-410.

Lafferty, Yvonne, and Jim McKay. "Suffragettes in Satin Shorts"? Gender and Competitive Boxing'. Qualitative Sociology 27, no. 3 (2004): 249-76.

Lantz, Jim. 'Family Development and the Martial Arts: A Phenomenological Study'. Contemporary Family Therapy 24, no. 4 (2002): 565-80. 
Lee, Jung Woo. 'Red Feminism and Propaganda in Communist Media: Portrayals of Female Boxers in the North Korean Media'. International Review for the Sociology of Sport 44 no. 2-3 (2009): 193-211.

Levine, Donald N. 'Martial Arts as a Resource for Liberal Education: The Case of Aikido'. In The Body: Social Process and Cultural Theory, edited by Mike Featherstone, Mike Hepworth and Bryan S. Turner, 209-24. London: Sage, 1991.

Levine, Donald N. 'The Liberal Arts and the Martial Arts'. Liberal Education 70, no. 3 (1984): 235-51.

Looser, Diana. 'Radical Bodies and Dangerous Ladies: Martial Arts and Women's Performance, 1900-1918'. Theatre Research International 36, no. 1 (2011): 3-19.

Looser, Diana. 'The "Risk Society" and Martial Arts Training in New Zealand'. Journal of Asian Martial Arts 15, no. 1 (2006): 8-23.

Martínez Guirao, Javier E. 'Una Aproximación Antropológica al Cuerpo Como Arma en las Artes Marciales'. Revista de Antropología Experimental 11 (2011): 113-25.

Matthews, Christopher R. "The Thrill Of The Fight": Towards a Sociology of Violence'. PhD diss., Loughborough University, UK, 2012.

Mayeda, David T., and David E. Ching. Fighting for Acceptance: Mixed Martial Artists and Violence in American Society. Lincoln: iUniverse, 2008.

McCaughey, Martha. Real Knockouts: The Physical Feminism of Women's SelfDefence. London: New York University Press, 1997.

McCaughey, Martha. 'The Fighting Spirit: Women's Self-Defence Training and the Discourse of Sexed Embodiment'. Gender \& Society 12, no. 3 (1998): 277-300.

McCree, Roy D. 'The Death of a Female Boxer: Media, Sport, Nationalism and Gender'. Journal of Sport and Social Issues 35, no. 4 (2011): 327-49.

McNaughton, Melanie J. 'Insurrectionary Womanliness: Gender and the (Boxing) Ring. The Qualitative Report 17, no. 33 (2012): 1-17.

Mennesson, Christine. 'Être une Femme dans un Sport Masculine: Modes de Socialisation et Construction des Dispositions Sexuees'. Sociétés Contemporaines 55 (2004): 69-90.

Mennesson, Christine. "Hard" Women and "Soft" Women: The Social Construction of Identities among Female Boxers'. International Review for the Sociology of Sport 35, no. 1 (2000): 21-33.

Noel, HarmoniJoie. 'Un-doing Gendered Power Relations through Martial Arts?' International Journal of Social Inquiry 2, no. 2 (2009): 17-37.

Paradis, Elise. 'Boxers, Briefs or Bras? Bodies, Gender and Change in the Boxing Gym'. Body \& Society 18, no. 2 (2012): 82-109.

Rao, Shridevi. 'Oos Sensai! Oos Sempai! A Karate School and Lessons on Inclusion'. International Journal of Inclusive Education 12, no. 3 (2007): 281-99.

Rhodes, James. 'Fighting for "Respectability": Media Representations of the White, "Working Class" Male Boxing "Hero". Journal of Sport and Social Issues 35, no. 4 (2011): 350-76.

Ryan, Alexandra. 'Globalisation and the "Internal Alchemy" in Chinese Martial Arts: The Transmission Of Taijiquan to Britain'. East Asia Science, Technology and Society: An International Journal 2, no. 4 (2008): 525-43. 
Ryan, Michael J. 'I Did Not Return a Master, But Well Cudgeled Was I: The Role of "Body Techniques" in the Transmission of Venezuelan Stick and Machete Fighting'. The Journal of Latin American and Caribbean Anthropology 16, no. 1 (2011): 1-23.

Saeki, Toshio. 'The Conflict Between Tradition and Modernization in a Sport Organization: A Sociological Study of Issues Surrounding the Organizational Reform of the All Japan Judo Federation'. International Review for the Sociology of Sport 29, no. 3 (1994): 301-15.

Samudra, Jaida K. 'Memory in our Body: Thick Participation and the Translation of Kinaesthetic Experience'. American Ethnologist 35, no. 4 (2008): 665-81.

Sánchez García, Raúl. 'Análisis Etnometodológico Sobre el Dinamismo del Habitus en Bourdieu y Elias Dentro del Desarrollo de Actividades Corporales'. REIS 124 (2008): 209-31.

Sánchez García, Raúl and Dominic Malcolm. 'Decivilizing, Civilizing or Informalizing? The International Development of Mixed Martial Arts'. International Review for the Sociology of Sport 45, no. 1 (2010): 39-58.

Sánchez García, Raúl and Dale C. Spencer, eds. Fighting Scholars: Habitus and Ethnographies of Martial Arts and Combat Sports. London: Anthem Press, 2013.

Schneider, Sara K. 'Learning India's Martial Art of Kalarippayattu: Unsettled Ecologies of Gender, Class, Culture, and Ethnicity'. Journal of Asian Martial Arts 19, no. 3 (2010): 46-63.

Searles, Patricia and Ronald J. Berger. 'The Feminist Self-Defence Movement: A Case Study'. Gender \& Society 1, no. 1 (1987): 61-84.

Sheard, Kenneth G. 'Aspects of Boxing in the Western "Civilising Process"'. International Review for the Sociology of Sport 32, no. 1 (1997): 31-57.

Sisjord, Mari K. 'Wrestling with Gender: A Study of Young Female and Male Wrestlers' Experiences of Physicality'. International Review for the Sociology of Sport 32, no.4 (1997): 433-38.

Sisjord, Mari K., and Elsa Kristiansen. 'Elite Women Wrestlers' Muscles: Physical Strength and a Social Burden'. International Review for the Sociology of Sport 44, no. 2-3 (2009): 231-46.

Sparkes, Andrew C. 'Martial Movement Sequences'. Bulletin of Physical Education 21, no. 1 (1985): 40-3.

Spencer, Dale C. 'Habit(us), Body Techniques and Body Callusing: An Ethnography of Mixed Martial Arts'. Body \& Society 15, no. 4 (2009): 119-43.

Spencer, Dale C. 'Narratives of Despair and Loss: Pain, Injury and Masculinity in the Sport of Mixed Martial Arts'. Qualitative Research in Sport and Exercise 4, no. 1 (2012): 117-37.

Spencer, Dale C. Ultimate Fighting and Embodiment: Violence, Gender and Mixed Martial Arts. London: Routledge, 2011.

Stephens, Neil, and Sara Delamont. 'Roda Boa, Roda Boa: Legitimate Peripheral Participation in Diasporic Capoeira'. Teaching and Teacher Education 26, no. 1 (2010): 113-18. 
Theeboom, Marc, and Paul De Knop. 'An Analysis of the Development of Wushu'. International Review for the Sociology of Sport 32, no. 3 (1997): 267-82.

Theeboom, Marc, and Paul De Knop. 'Asian Martial Arts and Approaches of Instruction in Physical Education'. European Journal of Physical Education 4, no. 2 (1999): 146-61.

Theeboom, Marc, Paul De Knop, and Jikkemien Vertonghen. 'Experiences of Children in Martial Arts'. European Journal for Sport and Society 6, no. 1 (2009): 19-35.

Van Bottenburg, Maarten, and Johan Heilbron. 'De-Sportization of Fighting Contests: The Origins and Dynamics of No Holds Barred Events and the Theory of Sportization'. International Review for the Sociology of Sport 41, no. 3/4 (2006): 259-82.

Van Bottenburg, Maarten, and Johan Heilbron. 'Informalization or De-Sportization of Fighting Contests? A Rejoinder to Raúl Sánchez García and Dominic Malcolm'. International Review for the Sociology of Sport 46, no. 1 (2011): 125-27.

Van Ingen, Cathy, and Nicole Kovacs. 'Subverting the Skirt: Female Boxers' “Troubling” Uniforms'. Feminist Media Studies 12, no. 3 (2012): 460-463.

Velija, Philippa, Mark Mierzwinski, and Laura Fortune. "It Made me Feel Powerful": Women's Gendered Embodiment and Physical Empowerment in the Martial Arts'. Leisure Studies, iFirst article, doi: 10.1080/02614367.2012.696128.

Vertonghen, Jikkemien, and Marc Theeboom. 'The Social-Psychological Outcomes of Martial Arts Practise Among Youth: A Review'. Journal of Social Science and Medicine 9 (2010): 528-37.

Wacquant, Loïc J.D. Body \& Soul: Notebooks of an Apprentice Boxer. Oxford: Oxford University Press, 2004.

Wacquant, Loïc J.D. 'Pugs at Work: Bodily Capital and Bodily Labour Among Professional Boxers'. Body \& Society 1, no. 1 (1995): 65-93.

Wilson, Lee. 'Jurus, Jazz Riffs and the Constitution of a National Martial Art in Indonesia'. Body \& Society 15, no. 3 (2009): 93-119.

Woodward, Kath. Boxing, Masculinity and Identity: The 'I' of the Tiger. Abingdon: Routledge, 2006.

Woodward, Kath. 'Rumbles in the Jungle: Boxing, Racialization, and the Performance of Masculinity'. Journal of Leisure Studies 23, no. 1 (2004): 5-17.

Wyrod, Robert. 'Warriors of the South Side: Race and the Body in the Martial Arts of Black Chicago'. Berkeley Journal of Sociology 44 (1999): 126-50.

Zarrilli, Phillip B. When the Body Becomes All Eyes: Paradigms, Discourses and Practices of Power in Kalarippayattu, a South Indian Martial Art. New Dehli: Oxford University Press, 1998. 